\title{
REDDy or not? The Effects on Indigenous Peoples in Brazil of a Global Mechanism for Reducing Emissions from Deforestation and Degradation
}

\author{
Nicholas Anderson \\ Department of Public Policy, University of North Carolina at Chapel Hill \\ Abernethy Hall, CB 3435, Chapel Hill, NC 27599-3435 \\ E-mail: nickanderson@unc.edu
}

\begin{abstract}
Deforestation in the tropics accounts for one-fifth of global greenhouse gas emissions. For this reason, the preservation of remaining tropical forests is an integral component of any international climate change mitigation policy. Indigenous peoples are crucial actors for the success of such a policy given the large amount of forestland in indigenous hands, their historical and cultural role in the management of forests, and their relative success at sustainable forest stewardship.

The aim of this research is to contribute to the academic literature and to the ongoing international debate over a mechanism for reducing emissions from deforestation and forest degradation (REDD), scheduled to culminate in December 2009 at the Copenhagen Climate Conference. This article aims to answer the question: What will be the effects on indigenous peoples in Brazil of an international policy mechanism for REDD? It draws upon research conducted using a qualitative prospective policy evaluation method to describe the possible risks and opportunities to indigenous peoples and to make recommendations for improving REDD on the variables of scope, financing, and the process of negotiation and governance.
\end{abstract}

Although the article concentrates on the effects of a REDD policy on indigenous peoples in Brazil given its status as a leading-edge case on this issue, it aspires to offer lessons for the other countries of the Amazon basin.

Keywords: Avoided deforestation, Brazil, Clean Development Mechanism (CDM), Climate change, Deforestation, Forest carbon, Indigenous peoples, Kyoto Protocol, Reduced emissions from deforestation and forest degradation (REDD)

\section{Introduction}

As governments grapple with the risk of grave climate change, the preservation of tropical forests is increasingly considered an integral component of any mitigation policy. It is in this policymaking context that indigenous peoples (Note 1), who have long been the most effective stewards of tropical forests, are emerging as potentially crucial actors.

The Kyoto Protocol, the global climate treaty negotiated in 1997, excluded deforestation-related sequestration as an eligible activity in the Clean Development Mechanism because of concerns about the permanence of carbon stocks in forests, the technical difficulty of monitoring and measuring forest carbon, and a perception among rainforest nations that inclusion would intrude on sovereignty. The countries of the world will meet in Copenhagen in December 2009 to negotiate a successor treaty to the Kyoto Protocol, which expires in 2012. Since the 1997 Kyoto negotiations, major developments have put deforestation on track to be included in the successor treaty: the emergence of new climate policy and financial mechanisms to enforce deforestation prevention commitments, improved measurement and monitoring technology, and the appearance of a coalition of rainforest nations willing to include deforestation in a way that does not intrude on sovereignty. In addition, recent scientific research demonstrates that preventing tropical deforestation is one of the most impactful actions available to mitigate climate change. This conclusion, plus economic research indicating the relative affordability of carbon sequestration via REDD compared to other mitigation methods, have put it at the top of the agenda for the Copenhagen Climate Change Conference. Incorporating indigenous peoples into the post-Kyoto treaty is important because of the large amount of forestland in indigenous hands, indigenous peoples' historical and cultural role in the management of forests, and their relative success at deforestation prevention vis-à-vis non-indigenous groups.

It is in this context that this article was researched and written. Although it focuses on the effects of REDD on indigenous peoples in Brazil, it aspires to offer lessons for the other Amazon basin countries of Bolivia, Colombia, Ecuador, Peru, Guyana, and Venezuela. The demographic, cultural, and political situations vary significantly across 
these countries, yet all are home to substantial indigenous populations who will be affected by REDD. Brazil was selected as a leading-edge case because it contains far more remaining tropical forest - and, consequently, more carbon sequestered in biomass - than any other country in the world. It also exhibits the second highest rate of deforestation and deforestation-related carbon dioxide emissions next to Indonesia. Brazil's indigenous populations, in general, are better organized and enjoy more secure land rights than their counterparts in neighboring countries.

Given the recent tensions between indigenous peoples and countries at the international level, the goal of this work is to move beyond non-communication toward engagement. Specifically, by focusing on objective policy design questions, it identifies possible pathways to agreement. In this way, this article may facilitate negotiations in Copenhagen.

\section{Literature review}

From the eighteenth century until 1950, the main sources of greenhouse gas emissions were the burning of fossil fuels (wood, coal, and oil) and the clearing of northern temperate forests that accompanied economic growth in Europe and North America. Since then cropland expansion has stabilized in the developed world but greatly accelerated in Latin America, Africa, and Southeast Asia (Forester et al., 2007). The locus of forest loss has shifted to the tropics, but deforestation remains an urgent problem if the world is to address climate change as it contributing 20 percent of global GHG emissions.

The reason the overuse, degradation, and wholesale clearing of forests have a pernicious climate change impact is because of the chemical makeup of plant life. Up to 50 percent of a tree's biomass is stored carbon. When a tree (or, to break it down, a trunk, branches, foliage, and roots) is destroyed, the stored carbon is released. Because large-scale deforestation is often conducted by the use of controlled fires, carbon that had been stored in plant matter literally goes up in flames - and settles in the atmosphere. Of course, this principle works in the other direction, making a standing rainforest one of nature's best defenses against rising atmospheric carbon dioxide. In the absence of human interventions, tropical forests and the biosphere generally sequester carbon dioxide from the atmosphere through photosynthesis and release it through respiration (Mahli, 1998; Foley \& Ramankutty, 2004). Compared to other zones, tropical forests are especially carbon dense; they contain approximately 60 percent of the total carbon stored in the biosphere (Sabine et al., 2004; Streck \& Scholz, 2006).

Forests' capacity to sequester large quantities of carbon dioxide makes them one of the best tools available to prevent drastic climate change. They provide two key services with regard to climate change: (i) as they grow absorbing the anthropogenic emissions from other sources, like fossil fuel combustion, thereby "subsidizing" against even more severe climate change, and (ii) storing large reservoirs of carbon - at least double the amount of carbon in the atmosphere is stored in tropical forests - whose release during deforestation triggers alarming increases in carbon emissions (Canadell \& Raupach, 2008).

It is clear that tropical forests have a crucial role in the carbon cycle and that deforestation contributes to climate change by elevating atmospheric carbon dioxide levels. But solving the problem of emissions from forest loss is complicated by political and policy hurdles. There disagreement over how to slow deforestation through international and domestic climate change policy. We now examine why deforestation was excluded from the Kyoto Protocol.

Despite their relevance to climate change, forests were poorly incorporated in the Kyoto Protocol. During the protocol's negotiation in 1997, the parties could not reach consensus on how to create an avoided deforestation mechanism. Efforts to include provisions in the Kyoto Protocol to allow avoided deforestation projects in the CDM were undermined by concerns about the permanence of forests, the technical difficulty of quantifying carbon stored in biomass, and forest accounting failures (Canadell \& Rapauch, 2008; Streck \& Scholz, 2006). The protocol nominally permits afforestation and reforestation projects to participate in the CDM but the methodologies for developing these projects are so burdensome that they have practically prevented any widespread development of afforestation or reforestation projects (Note 2). A total of eight afforestation or reforestation projects have been successfully added to the CDM registry, comprising 0.35 percent of total projects through October 2009 (United Nations Framework Convention on Climate Change, 2009).

The permanence concern arises from the fundamental difference between projects that reduce emissions by altering land use and reduction projects in other sectors (Streck \& Scholz, 2006). Simply, the difference is that carbon sequestered by land use management remains a benefit only as long as it remains sequestered, whereas other emissions reductions projects remain a benefit in perpetuity. Consider the distinction between a project that stores carbon in a forest grove, which could be felled by fire, insects, or log poachers, and a technology installed in a power plant that immediately and permanently reduces the amount of carbon dioxide the plant emits. Reaching political agreement on the permanence risk of land use projects, and forestry projects in particular, proved impossible at Kyoto.

The second difficulty that undermined forestry at Kyoto was the technical difficulty of measuring the amount of carbon stored in biomass. Measuring the carbon stored in forests was controversial and difficult until recently (for an example, consider debate in the scientific literature between Brown \& Lugo and Fearnside in the 1990s). 
The third important concern that the literature identifies concerns forest accounting failures. Deforestation is principally driven by logging, population growth and migration, biofuel production, and agricultural expansion; preventing one of these activities from occurring in one place might simply move it to occur in another (Murray, 2008). This concept, called leakage, explains that carbon credits generated by forestry projects might represent false reductions if the prevented deforestation goes on to take place elsewhere.

At Kyoto and in subsequent negotiations, deforestation was a divisive issue. As Streck and Scholz (2006) document, European environmental NGOs were the most visible campaigners against including deforestation, a position that ultimately influenced the stance of the EU countries. In their view, "Climate change is a problem that should be addressed primarily through reducing the world's dependence on fossil fuels," explained Streck and Scholz (2006). Including forestry would undercut that priority. Fossil-fuel reduction, renewable energy and energy efficiency projects were often viewed as more "effective." Non-tropical countries were concerned that including forests would let heavily forested countries off the hook when it came to serious emissions reductions, especially because the magnitude of the carbon stored in forests is so large. Likewise, Canada and other developed countries anxious about climate change impacts worried that a flood of cheap, weakly-regulated credits from forest projects would flood the market, driving down the price of carbon credits and crowding out more meaningful activities (World Wildlife Foundation, 2003). Attempts to include deforestation were further hindered by Brazil, which argued that a strong international policy on deforestation would interfere with domestic environmental policy-making and sovereignty (Ritvo, 2008)..

It was in this context that deforestation was left out of the Kyoto Protocol's CDM when it was negotiated in 1997. But since then, three major developments have boosted the likelihood that deforestation will be included in the successor treaty to the Kyoto Protocol, which expires in 2012: technical progress on carbon measurement and rainforest monitoring, the development of new climate policy and financial mechanisms, and the emergence of a coalition of rainforest nations expressing willingness to include deforestation in a way that does not intrude on sovereignty (Gullison et al., 2007). These developments appear to address the crucial stumbling blocks at Kyoto.

New scientific literature raises the stakes on the drive to include forests in the treaty, making the case that their preservation is even more important than initially imagined. We have always known that tropical forests provide important services such as preserving biodiversity, wildlife habitat, and water. But recent ecological studies show climate change eroding these benefits. On the topic of biodiversity, the findings of Miles et al. (2004), for example, imply an urgent need to preserve tropical forests. Their simulation of climate change impacts on the Amazon basin found that, under a scenario assuming a 1 percent annual increase in carbon dioxide emissions, 43 percent of plant species will become non-viable. And a potentially paradigm-changing recent article by Jackson et al. (2008) that indicates the unambiguous climate benefits of preserving tropical forests compared to other ecosystems. In it, they argue that research (and policy-making) on climate has largely ignored the biophysical factors of forests, such as reflectivity and evaporation, even though these factors have a larger influence on temperatures than carbon sequestration. For example, because forested areas are darker than pastures or snow-covered surfaces, they increase the absorption of sunlight, leading to local warming. With lighter surface colors (because of grasses, snow cover, or cloud cover, for example) comes a greater albedo effect, meaning that less sunlight is absorbed as heat, thereby reducing warming. As such, Jackson et al. (2008) are cautious about increasing reforestation efforts in temperate and especially boreal forests, since darker surface patterns may in fact be detrimental (because is in these areas new forests might be displacing snow). In the tropics, however, Jackson et al. (2008) conclude that reforestation and prevented deforestation will have a cooling effect not only through prolific carbon sequestration but also through evaporation and the build-up of clouds. Jackson et al. (2008) write,

[A]voided deforestation, forest restoration, and afforestation in the tropics provide the greatest value for slowing climate change. Tropical forests combine rapid rates of carbon storage with biophysical effects that are beneficial in many settings, including greater convective rainfall.

The ecology literature is not alone in identifying that tropical forests, perhaps more than any other ecosystem or sector, have the greatest value in slowing climate change. Recent work in economics also shows that preserving rainforests represents one of the largest and least expensive GHG abatement strategies. Canadell and Rapauch (2008) note that approximately 500 million tons of carbon dioxide can be sequestered per year through forest activities (including not only avoided deforestation but also reforestation) at a cost of US\$20 per ton. Nepstad (2007) uses a different methodology than the one referenced by Canadell \& Rapauch (2008), only examining avoided deforestation potential, and predicts that a price of US\$5.50 per ton of carbon would be sufficient to preserve all of the remaining tropical forests in Brazil and, consequently, the estimated 47 billion tons of carbon they contain. That compares with the current price of carbon dioxide on the regulated European market of US\$16 per ton. This economics literature is synthesized in a recent draft for the Union of Concerned Scientists by Boucher (2008) that concludes that half of world emissions from deforestation can be reduced at a third of the current market prices for carbon. Although there is not perfect harmony in 
the economics literature on the price of carbon from avoided deforestation, there is broad agreement that, at least initially, it is an inexpensive option compared to reducing emissions from fossil fuels (Note 3).

To this point, we have identified the aggravating role deforestation plays in climate change. We now explore the relevance of indigenous peoples to forest management. But rather than relying on any cultural assumption about indigenous peoples' effectiveness or ineffectiveness at forest stewardship, we examine the ecological literature for an answer. Anecdotal evidence of indigenous tribes taking poor care of the land on which they live created a skewed perception. In the early part of this decade, several studies suggested that the ability of indigenous peoples to prevent deforestation on their lands was diminished as population densities increased and as they adapted to the national society's market orientation (Terborgh, 2000; Redford \& Sanderson, 2000). Yet more recent studies are driving a paradigm shift toward recognizing and embracing indigenous and local land management practices (Kothari, 2008). One important study, by Ferreira et al. (2005), refuted the widely-held hypothesis that protected areas and indigenous lands in Brazil do not correspond with improved forest conservation. The study assessed deforestation that occurred within or near protected areas and indigenous reserves in the states of Mato Grosso, Rondônia, and Pará and that made up 90 percent of the deforestation that occurred in the region from 2001 to 2003 . The results showed that deforestation was 10 to 20 times less within indigenous lands and protected areas than in adjoining areas. In other words, indigenous lands and federally protected areas act as an effective buffer against deforestation. A subsequent study by Nepstad et al. (2006) reinforced and added depth to these findings. This showed that the indigenous lands that do exhibit high rates of deforestation are located within the active agricultural frontier - often along a road - and that the deforestation was caused by exploitation or invasions by outsiders. In contrast to the earlier studies, data from Nepstad et al. (2006) indicate that it is possible for indigenous peoples to have connections with the national society and still maintain their forest resource. The indigenous tribes that successfully inhibit deforestation, even if their reserves are located within the agricultural frontier, are those that enforce legal restrictions on non-indigenous forest exploitation. In recent years, some tribes have done so by defending land with force, taking intruders hostage to demand reserve demarcation, or simply soliciting government assistance with border protection.

To summarize, new consensus is emerging that indigenous lands are effective buffers against deforestation. Where deforestation does occur on indigenous lands, it is at the hands of non-indigenous intruders. And the indigenous lands with the least deforestation are those settled by tribes who defend their territories against illegal takings. In short, indigenous peoples can be the most effective stewards of the rainforest. Nepstad et al (2006) conclude that "the ecological integrity of the indigenous lands will ultimately depend upon cultural factors and on the economic alternatives that are available to indigenous peoples" (p. 71). This is all the more reason for a well-designed REDD mechanism that creates economic opportunities for indigenous peoples in sustainable forest management.

\section{Research Methods}

\subsection{Study Method}

The research that informs this article was a prospective policy evaluation, reflecting the forward-looking nature of the question. The purpose of prospective research is to provide an understanding ahead of time of how a policy is likely to work. This article seeks an understanding ahead of time how a REDD proposal is likely to work in practice for indigenous peoples in Brazil. The research involved: (i) textual analysis of the policy proposals, (ii) collection of original data through qualitative interviews with key informants using the interview guide approach, and (iii) content analysis of the collected data. The original data were collected through qualitative interviews with "experts or key informants [who were] selected primarily or solely by considerations such as knowledgeability and appropriate diversity" (GAO 1990, p. 87). Prospective policy analysis is fundamentally a time-driven approach, reflecting the need to generate conclusions about a policy proposal currently under consideration.

\subsection{Study Sample}

Over 12 percent of Brazil's land area - more than 1,055,000 square kilometers - is demarcated as indigenous reserves, and nearly all of that remains as pristine forest. Wunder (2007, p. 53) identifies four reasons why indigenous tribes preserve the forest:

Their forest clearing does not exceed regrowth because population density is low, human mortality is high, production technology is rudimentary, and because they treasure the forest for its cultural values.

In short, this article focuses on indigenous peoples because of their role in rainforest stewardship and based on the assumption that their effective participation will augment the possibility of success of any future policy.

The decision to study the indigenous peoples of Brazil was made because Brazil is a "snowball" case in the debate over an international policy for deforestation, a leading-edge case likely to influence the larger body. Brazil is a leading-edge case because of its size, outsize share of remaining tropical forest, and influence in the international climate negotiations. Ultimately, this article aspires to improve the way REDD is designed to create better outcomes for indigenous peoples across the Amazon Basin. Although 60 percent of the Amazon rainforest lies within Brazil, it also reaches into Bolivia, 
Colombia, Ecuador, Peru, Guyana, and Venezuela. Each of these countries is home to a substantial indigenous population.

Study participants included 12 individuals identified as experts on this issue. All participants were selected for their issue expertise; none were drawn from the study population. The criteria for selection were familiarity with both indigenous peoples in Brazil and with the ongoing negotiations over REDD policy. The majority of participants represented research non-governmental organizations (NGOs) or universities.

\subsection{Limitations}

The narrowness of my study population, indigenous peoples in Brazil, limits the generalizability of my findings. Brazil's size, property rights regime, economic and political situation, and other factors make it unique. The findings here will not necessarily hold true in all other Amazon countries.

Since the majority of participants were educated or based in Western, developed countries, there is a clear over-representation of certain cultural tendencies. This might bias my findings toward particular types of anticipated problems or policy options. This is mitigated somewhat by the fact that, of the Western participants, the majority spend significant portions of their working time in Brazil and/or in the field. In general, relying on elites reduces the heterogeneity of expertise and experience included in a study. The participants represented at least five nationalities and were based in four countries. Even so, interviewing elites runs the risk drawing on only one shared viewpoint. Additionally, because of the qualitative nature of the interviews, the answers elicited may be subjective or speculative. Taken together, these weaknesses limit the completeness of my conclusions. This article is not only prospective but also exploratory in nature. In seeking to answer one question, it raises ten more that merit future consideration.

\section{Discussion}

This section places the themes that emerged from the interviews in four categories.

\subsection{Incentives}

If the aim of a REDD scheme is to prevent emissions from deforestation, the policy might only include stands of forest that are at immediate risk. Forests on indigenous territories are often the least threatened of all. This is one of the largest impediments to the inclusion of indigenous peoples in a system for avoided deforestation projects and was the theme most commonly mentioned by participants in the interviews for this article. If the policy insists on a strict test of additionality in which only clearly threatened areas are eligible, many indigenous lands would be excluded. As one participant noted, "Paradoxically that ends up focusing your attention on bad behavior." Crucial challenges in REDD policy design are to prevent deforestation without creating a perverse incentive to threaten forests and to reward successful forest stewards like indigenous peoples.

\subsection{Risks to communities}

- Five participants said that the greater levels of engagement with the external world necessitated by a REDD project could cause cultural deterioration for tribes. Two participants said that such a view was paternalistic; policy should instead focus on ensuring that when contact does happen, it is more productive.

- Because indigenous peoples clear forest to cultivate food and raise cattle, REDD could force communities to move away from traditional agricultural practices that involve the destruction of forest. Ideally REDD projects should change agriculture in positive ways, e.g. encouraging a tribe to use previously cleared land more efficiently rather than clearing new land.

- There is a risk that tribes enroll such a high amount of their territory in REDD projects that they not only abandon their traditional agricultural practices but are legally unable to engage in them. Under this scenario, REDD payments could end up compensating indigenous communities not to cultivate plants or to raise livestock at all. They would effectively import all of their food, thereby becoming dependent upon REDD payments and external producers.

- The way the policy is designed could also create new pressures on indigenous land. The adoption of a REDD scheme would suddenly assign a tremendous amount of economic value to a resource that has been in many places close to worthless. This shift would increase the risk of illegal land grabbing, border disputes, and the loss of land for indigenous groups living on land for which they do not hold clear title.

- The sudden increase in forests' economic value could create internal conflict over how to control the resource. Other governance risks raised by participants include internal abuse, corruption, and embezzlement by firms or the government. Almost all participants thought these would be potential concerns but ones that could be addressed with the right suite of safeguards. 


\subsection{Benefits to communities}

Despite the catalogue of risks above, participants were on the whole largely positive about REDD's implications for indigenous peoples. Many participants echoed this comment: "I think [indigenous peoples] have a lot to gain by a REDD policy. I think they have a fair amount to lose in the sense of lost opportunity if a REDD policy is not implemented." Beyond ownership of a newly valuable asset, these participants pointed to benefits such as new streams of income, improved public goods such as health and education, new skills in forest monitoring and business administration, and recognition of their stewardship role as benefits that indigenous peoples stand to receive. Perhaps most importantly, indigenous peoples' desire to preserve their forest lifestyle will be reinforced as future threats to deforestation are minimized.

\subsection{Design and implementation process}

Participants talked about communication, education, and capacity building as crucial procedural steps in the design of a REDD policy. There was divergence on whether communities should be engaged at a grassroots level or if engagement should be at a higher level. Said one: "High level capacity building and engagement needs to take place [to] strengthen core groups of negotiators from some of the representative indigenous organizations" to create institutional experience among indigenous communities. One participant made it clear that the process should not confuse consultation with participation. As they have been demanding all along, indigenous peoples should be included in the design, governance, and distribution of benefits of a REDD mechanism. Another participant called for a negotiation process that does not assume all knowledge is flowing in one direction. If indigenous peoples have been so successful at preserving forests, perhaps market-oriented societies could learn from indigenous practices. Besides, at a cultural level, indigenous peoples respond to reciprocity, an observation that could help facilitate negotiations. Indigenous groups might be less antagonistic if "states could behave a bit like individuals in terms of thinking about their carbon responsibilities."

\section{Policy recommendations}

This section identifies the implications for policy of the themes discussed above. The principal recommendations concern REDD scope, financing, and process. Scope refers to the types of forest management activities included in the REDD regime, financing refers to the mechanisms for delivering funding to REDD projects, and process describes the procedure for negotiating and governing a REDD mechanism.

\subsection{Policy recommendations for scope}

In leading proposals under consideration at Copenhagen REDD is variously defined in three ways, each one representing a marginally wider scope.These alternatives are labeled RED, REDD, and REDD+.

- RED would credit only those projects that reduce emissions from deforestation

- REDD would allow projects that reduce emissions from deforestation and forest degradation

- REDD+ would consider projects that reduce emissions from deforestation and degradation as well as those that enhance the carbon stocks in forests, such as reforestation and afforestation (Note 4)

Among participants, there was near universal agreement that RED is the alternative with the least possible net benefits to indigenous peoples and REDD + is the alternative with the greatest potential. Because forests on indigenous territories are not under threat of full-scale deforestation, the effects of a RED policy on indigenous peoples would be minimal. They would not stand to benefit directly.

There would be some project opportunities under REDD because some degradation activities occur on indigenous lands, such as, according to one participant, clearing for pastures or gardens, allowing loggers to enter the reserve, and loggers entering illegally and taking high-value trees.

The broadest alternative, REDD+, would bring not only all of the effects noted earlier for the other alternatives but also greater income potential because indigenous peoples would have the opportunity to engage in projects that reforest tracts of land. (Voluntary REDD+ projects piloted by NGOs and indigenous groups are already occurring.) Risks of the REDD+ approach include worries about locked-in land use obligations. A reforestation project that is agreed to without a complete understanding of its meaning could obligate a tribe to maintain the forest at the expense of agriculture and nutrition.

These are the effects on indigenous peoples of the different alternatives for scope. This article offers the following recommendations to improve the scope alternatives from the perspective of indigenous peoples.

- To address the risk that projects might inhibit tribes' land use, a policy should include a carefully considered definition of both degradation and reforestation. The ideal policy would encourage tribes to conduct agriculture efficiently (that is, without having to degrade as much land) and sustainably. Similarly, reforestation should be defined as projects that restore forests to their natural state using native species. No REDD policy should allow commercial tree plantations or reforestation projects with non-native species. 
- To reduce the risk that indigenous peoples will abandon traditional subsistence activities and become dependent upon REDD payments, policy should be designed to foster new revenue-generating activities, such as sustainable timber logging, agroforestry, and the commercialization of non-timber forest products (like growing fruits, nuts, and coffee within a standing forest).

- To best meet the interests of indigenous peoples, the broadest alternative possible, REDD+, should be adopted. With a broader scope come more risks like land use obligations and dependency, but each of those risks could be mitigated through policies like strict definitions of degradation and reforestation.

\subsection{Policy recommendations for financing}

The second major policy variable asks: where does the funding for projects come from? The three basic alternatives for financing are:

- A direct market approach that allows firms in developed ("Annex 1") countries to purchase credits from REDD projects to meet their domestic requirements under a trading scheme; this could include offsetting.

- A government fund approach, under which REDD credits are not offsets. Instead, developed country governments or firms make transfer payments to tropical country governments which then develop REDD projects domestically.

- Voluntary funding that is provided by governments, firms, or individuals to REDD projects without a reciprocal exchange of a credit to meet any compliance target.

In identifying the ideal financing policy from the perspective of indigenous peoples in Brazil, participants were largely divided between a direct market approach and government fund approach. Those who preferred a direct market said it would generate greater potential funding because of its tie-in with trading (or similar emissions reduction) regimes in Annex 1 countries. Additionally, since REDD projects would be developed independently in a direct market, buyers would have choices. The flexibility of choice could bring "gourmet" buyers (i.e. those interested in projects with social co-benefits) to indigenous peoples. Finally, while a direct market would bring some cultural and corruption risks for indigenous peoples, these could be mitigated with strong standards and excellent capacity building.

Challenges associated with a direct market include:

- It is an offset market by design and indigenous peoples are skeptical about policies that allow developed countries to offset their emissions rather than making real reductions.

- The potential for one-time payments that are not sustained over time. Beside the governance risks of a lump sum transfer to a rural subsistence community, the concern is that the communities would then have no sustained incentive to preserve.

- The negative cultural influence of engagement with external, market-driven actors.

To address these concerns, there are three specific policy recommendations to improve a direct market approach.

- There is little natural incentive for transparency among sellers of REDD credits, especially given the time, resources, and technical expertise necessary for developing a REDD project. This lack of transparency could be injurious for indigenous tribes if developers use unfavorable contracts. The government of Brazil should prepare a publicly available sample contract that would include the highest standards of community engagement and protections. This contract would be the default contract for projects involving indigenous peoples and could directly address some of the risks noted earlier such as corruption, cultural degradation, and commercial confidentiality.

- A second recommendation is the need for some level of regulation. To be credited, every project should be required to prove it was developed with authentic stakeholder outreach, that the community is included in the distribution of benefits, and that abusive relationships with indigenous peoples and other local peoples are prevented.

- A final policy recommendation is to include a mechanism for sustained payments over time with the goal of increasing community capacity, reducing corruption, and ensuring forest permanence. Payments should be made over the entire course of the contract, whether 15 or 90 years. All participants familiar with indigenous communities said that sustained, low-value funding would be better than one-time, high-value funding.

Although the direct market approach would have the potential to mobilize greater amounts of money for forest conservation, there is no guarantee those funds would reach indigenous peoples. For indigenous peoples, therefore, a government fund approach might be more beneficial. The Brazilian government (Note 5) would receive transfer payments from foreign firms and countries and direct those monies to REDD projects in Brazil. The government could prioritize indigenous lands even if not under immediate threat. However there is significant potential for corruption, embezzlement, and government inefficiency. 
For its proponents, the government fund approach is attractive because it would protect indigenous peoples from the worst elements of the market and enable them to work consultatively to develop projects at their own speed. Tribes are accustomed to interacting with FUNAI, the Brazilian Indian Agency. Unlike the direct market, which would be populated by price-driven buyers seek to minimize a project's development and community training costs, the government's goals are broader that simply cost-consciousness and it could be a better partner for tribes.

Despite its benefits, the government fund approach would not generate the same levels of funding and might not be as sustainable over time, especially if it is not tied to an offset mechanism. For indigenous peoples looking to REDD as a solution for protecting the Amazon basin in perpetuity, a government fund might disappoint. Corruption, embezzlement, and government inefficiency are other risks.

Policy suggestions to improve a government fund approach include:

- To reduce corruption and embezzlement risk, rather than conceiving of the government fund as a simple federal program, it should draw upon a number of stakeholders. This regulatory intermediary would be jointly administered by the government and civil society. One model could be the UN Development Program's Small Grants Program, which has a national steering committee with a non-governmental majority (e.g. members from academia, NGOs, the private sector, indigenous communities themselves).

- Other ways to promote the equitable and efficient use of funds include oversight by the UN and required disclosure accounting for how funds were used. One idea is to have tropical countries compete for REDD financing on the idea that those with the most efficient systems would rise to the top. Governments would be judged on a dollar-to-acres-saved ratio; the governments that are most effective in using funds for forest protection would be rewarded. This is an idea that the government of Brazil has supported.

The final financing alternative would be to rely on a purely voluntary market in which individuals, firms, and governments support REDD activities for reasons of conscience, charity, or image. The voluntary market is what has existed to date (Note 6).

Under a voluntary market, the risks to indigenous peoples would be fewer and the quality of the projects higher, although the amount of available funds would be drastically less than under the other alternatives. The voluntary market is not directly relevant to the negotiations over an international REDD policy and independently it is not a long-term solution to deforestation. It is valuable in so far as it allows the development of pilot projects. Pilot projects help indigenous communities, as well as state and national governments, learn lessons and anticipate possible challenges of working with REDD projects. The voluntary market will be complemented by whatever REDD policy is agreed to at Copenhagen; between December 2009 and the expiration of the Kyoto Protocol in 2012 it will be an important laboratory for refining the new mechanism. Beyond 2012 voluntary projects, especially those with high biodiversity or community benefits, will continue to exist simultaneously and to attract "gourmet" buyers.

In this section, we considered the three alternatives for REDD financing. In looking at the financing mechanisms independently, however, we miss an important point: it is possible, perhaps even likely, that the ultimate policy will allow some combination. Aside from the continued existence of the voluntary market, it is possible that the Copenhagen conference may agree to a hybrid of the market and government approaches. The government fund approach may be an intermediary step as countries develop their internal capacity to oversee project quality and prevent leakage, and as communities and interested parties grow their understanding of REDD.

\subsection{Policy recommendations for the process of negotiation and governance of a REDD regime}

Indigenous peoples have been largely excluded from the design of a REDD policy to this point and demand inclusion because it is highly relevant to them. The recommendations in this section are more political in nature, drawing upon the theory of negotiation.

The Poznań Climate Conference in December 2008 was meant to prepare parties for the real work at Copenhagen a year later. As at Bali in 2007, it was apparent at Poznan that REDD policy is highly important to indigenous peoples and that they felt excluded from the process of negotiating it. The nature of the international governance system is such that national governments are the only official parties to the climate treaty negotiations. Indigenous representatives at Poznań protested in the hallways after Australia, Canada, New Zealand, and the United States refused to include a commitment to the UN Declaration on the Rights of Indigenous Peoples in the draft agreement.

To incorporate indigenous voices into policy design and implementation process, this article recommends:

- Recognize the rights of indigenous peoples through text targeted to address specific concerns rather than vague language. At Poznań, leading countries opposed including guarantees that REDD policy would comply with the relatively broad-ranging UN Declaration on the Rights of Indigenous Peoples (UNDRIP). The United States, Canada, Australia, and New Zealand have substantial indigenous populations, although they do not live in tropical forests. These countries' rationale in opposing inclusion of UNDRIP guarantees was that doing so 
could contradict existing domestic laws regarding indigenous peoples and that UNDRIP has "nothing whatsoever to do with climate change" (Curry \& Mittelstaedt, 2008).

- Indigenous groups at Poznań were outraged and today some activists still refuse to proceed in the REDD process without a guarantee that their rights will be protected. To overcome this impasse, look to the Convention on Biological Diversity, an international treaty for the conservation of biodiversity and the equitable sharing of its genetic resources that was adopted in June 1992. Not only was the design process of CBD inclusive of indigenous peoples (e.g. they were permitted to hold the floor and to participate in debate), but the document itself includes two clauses that deal directly with indigenous peoples (Note 7). Article 8, Clause $\mathrm{J}$ calls for the respect and preservation of the "innovations and practices" of indigenous communities and "the equitable sharing of the benefits arising from the utilization of such knowledge, innovations, and practices." Article 10, Clause C protects encourages "customary use of biological resources in accordance with traditional cultural practices." A similar middle ground should be sought for REDD policy.

- Rather than being prevented from participating, indigenous peoples should be allowed to participate in discussions, understanding that they will not be eventual signatories but are important parties with a stake in the outcome.

- Once a REDD policy has been adopted, indigenous peoples should be included in its governance. For the most part, indigenous people see REDD as a positive opportunity and want to be a part of the ultimate regime. The earlier example of the UNDP Small Grants Program, in which national steering committees include representatives of all interested parties, could be a good model.

- Indigenous people should be trained in advanced forest monitoring so that they can conduct these activities themselves. One of the critical success factors from the indigenous perspective is that the ultimate REDD policy include resources devoted to this sort of capacity building.

- Finally, the governance process should include a mechanism for facilitating land tenure claims. A key risk identified in the research for this article is that a REDD policy will assign tremendous economic value to forest assets, and that pending or disputed land claims would be ignored, forcing indigenous peoples without legal title off their heritage territory. Land tenure issues are not as pressing a concern for indigenous peoples in Brazil as for indigenous peoples elsewhere. The interests of indigenous communities worldwide would be furthered if the REDD policy encouraged preserving the integrity of existing land titles, fast-tracking pending land claims, and protecting indigenous communities from land expropriation, without infringing on national sovereignty over land use decisions.

\section{Conclusion}

This article is based on the understanding that any serious climate change policy must address deforestation because of its significant greenhouse gas emissions. Indigenous tribes are relevant primarily because of the large amount of remaining tropical forest they control. As one interview participant explained, "REDD will never succeed... without the involvement of the [communities] that are making decisions every day as to whether to cut a tree down or leave it standing."

Drawing upon qualitative policy research, this article explored the possible effects on indigenous tribes in Brazil of an international mechanism for reducing emissions from deforestation and degradation. It provided a prospective outlook of potential problems and benefits of various policy options and recommendations to improve them. Although the focus is indigenous tribes in Brazil, it hopes to inform policymaking in other countries of the Amazon basin.

More research is warranted on the implications of REDD for indigenous peoples and how to best incorporate them into the global climate change treaty. This remains largely unexplored terrain. For example, a program evaluation of voluntary REDD projects that have been implemented around the world to date would yield highly useful findings. Beyond questions related to the climate change treaty, future work might also investigate the sustainable forest management practices of indigenous people with the goal of offering lessons to non-indigenous societies.

\section{References}

Boucher, D. (2008). What REDD can do: The economics and development of reducing emissions from deforestation and forest degradation." Unpublished (draft for external review). Union of Concerned Scientists.

Brown, S. \& Lugo, A.E. (1982). The storage and production of organic matter in tropical forests and their role in the global carbon cycle. Biotropica, 14 (3), 161-187.

Brown, S. \& Lugo, A.E. (1992). Above-ground biomass estimates for tropical moist forests of the Brazilian Amazon. Interciencia, 17 (1), 8-18

Canadell, J. G. \& Raupach, M.R. (2008). Managing forests for climate change mitigation. Science, 320,1456-1457. 
Convention on Biological Diversity. (1993). Articles 8 \& 10.

Curry, B. \& Mittelstaedt, M. (2008, December 12). Ottawa's stand at climate talks hurting native rights, chiefs say. The Globe and Mail.

Fearnside, P.M. (1992). Forest biomass in the Brazilian Amazon: comments on the estimate by Brown and Lugo. Interciencia, 17 (1), 19-27.

Fearnside, P.M. \& Laurance, W.F. (2004). Tropical deforestation and greenhouse-gas emissions. Ecological Applications, 14 (4), 982-986.

Ferreira, L.V., et al. (2005). O desmatamento na Amazônia e a importância das áreas protegidas. Estudos Avançados 19 (53), 157-166.

Foley, J.A. \& Ramankutty, N. (2004). A primer on the terrestrial carbon cycle: What we don't know but should. The Global Carbon Cycle: Integrating Humans, Climate, and the Natural World. Washington, D.C.: Island Press: 279-294.

Forester, P., et al. (2007). Changes in atmospheric constituents and in radiative forcing. Climate Change 2007: The Physical Science Basis. Contribution of Working Group I to the Fourth Assessment Report of the Intergovernmental Panel on Climate Change. UN Intergovernmental Panel on Climate Change.

General Accounting Office. (1990). Prospective Evaluation Methods: The Prospective Evaluation Synarticle.

Gullison, R.E., et al. (2007). Tropical forests and climate policy. Science, 316, 985-986.

Jackson, R.B., et al. (2008). Protecting climate with forests. Environmental Research Letters, 3.

Kothari, A. (2008). Protected areas and people: The future and the past. Parks, 17(2), 23-34.

Malhi, Y., et al. (1998). Carbon dioxide transfer over a Central Amazonian rain forest. Journal of Geophysical Research, 103 (D24).

Marrakesh Accords. (2001). Article K, Section 1, Annex A.

Miles, L., et al. (2004). The impact of global climate change on tropical forest biodiversity in Amazonia. Global Ecology and Biogeography, 13 (6), 553-565.

Murray, B.C. (2008). Leakage from an avoided deforestation compensation policy: Concepts, empirical evidence, and corrective policy options. Working Paper 08-02, Nicholas Institute for Environmental Policy Solutions.

Nepstad, D., et al. (2006). Inhibition of amazon deforestation and fire by parks and indigenous lands. Conservation Biology, 20 (1), 65-73.

Nepstad, D., et al. (2007). The costs and benefits of reducing carbon emissions from deforestation and forest degradation in the Brazilian Amazon. Woods Hole Research Center.

Redford, K.H. \& Sanderson, S.E. (2000). Extracting humans from nature. Conservation Biology, 14 (5), 1362-1364.

Ritvo, J. (2008). Contemporary Brazilian government efforts to address the Amazon paradox. Council on Hemispheric Affairs.

Sabine, C.L., et al. (2004). Current status and past trends of the global carbon cycle. The Global Carbon Cycle: Integrating Humans, Climate, and the Natural World: 17-44.

Streck, C. \& Scholz, S.M. (2006). The role of forests in global climate changes: whence we come and where we go. International Affairs, 86 (5), 861-879.

Terborgh, J.W. (2000). The fate of tropical forests: a matter of stewardship. Conservation Biology, 14 (5), 1358-1361. United Nations Framework Convention on Climate Change. (2009). Distribution of registered projects activities by Wunder, S. (2007). The effects of payments for environmental services in tropical conservation. Conservation Biology, 21 (1), 48-58.

World Wildlife Foundation. (2003). Giving credit where credit is due: Canada, Kyoto, and Developing Countries. 


\section{Notes}

Note 1. This article uses the term "indigenous peoples," instead of "indigenous people," to conform to internationally accepted language as codified in the 2008 UN Declaration of the Rights of Indigenous Peoples.

Note 2. We use "reforestation" to mean restoring degraded lands to their prior state as forests and "afforestation" to mean creating forests in areas that were not previously forested.

Note 3. The Nepstad (2007) estimate should be lower because it includes only the opportunity cost. Looking at the Canadell and Rapauch (2008) predictions alongside the Nepstad predictions is an apple to oranges comparison.

Note 4. The Marrakesh Accords (2001) define deforestation as the direct human-induced conversion of forested land to non-forested land. To be considered a forest, the area must be greater than 0.05 hectares, have a tree cover of over 10 percent, and have trees that at maturity reach a minimum height of 2 to 5 meters. In other words, deforestation is the depletion of forest to below 10 percent tree cover. Degradation, by contrast, includes all activities that deplete forests to a point above total tree cover of 10 percent. Enhancement of carbon stocks includes activities that increase the carbon density of the land, often through reforestation of previously degraded forest. These are working definitions and must be defined more specifically in the post-Kyoto treaty.

Note 5. The Brazilian government is one of the original proponents of this approach. In July 2008, with a pledge of up to $\$ 1$ billion from Norway, President Lula da Silva launched the Amazon Fund to invest in pilot REDD projects. The fund has not yet disbursed any monies and is working with a state-controlled development bank to design the REDD process.

Note 6. There is no precise count of how many voluntary REDD projects have been conducted in Brazil because broader philanthropic rainforest-protection donations have a long history in the country. In recent years, several pure REDD projects have been developed by international environmental NGOs with corporate backing, but that activity has slowed as corporate donors await the results of Copenhagen conference.

Note 7. Importantly, Canada, Australia, New Zealand, and the United States supported the CBD. 